\title{
Technical and Economic Analysis on Renewal of Shipborne Measurement and Communication Equipments
}

\author{
Zhang Yongliang, Zhou Jiang, Liu Xiaochun, Xue Jun \\ Joint Laboratory of Ocean-based Flight Vehicle Measurement and Control \\ China Satellite Maritime Tracking and Control Department \\ Jiangyin, China \\ e-mail: zylelet2000@yahoo.com
}

\begin{abstract}
Shipborne measurement and communication equipments are central parts of space measurement ship. Renewal of the equipments is very important for space measurement tasks. Also it is important to save cost for continuable development. The paper proposes the problem of technical and economic analysis of the renewals. The maintenance and update with their analysis are introduced too. Finally schemes of the renewal and its decision-making method are presented. The renewals are motivated mostly by requirement of space missions at present. But for continuable development the ratio of efficient and cost is important. The decision-maker may refer the paper and select scientific renewal scheme.
\end{abstract}

Keywords- Technical and economic analysis; measurement and communication equipments; space measurement ship; less present value of overall cost

\section{INTRODUCTION}

Space measurement ships are parts of Chinese space measurement and control network. Measurement and communication equipments are most important parts of space measurement ship "Yuan Wang". They track, telemetry and control space vehicles, such as man-made satellites and "Shenzhou" spaceship, and communicate with Central Control Station. So for accomplishing space measuring and control tasks successfully, renewing of the equipments is very important.

Comparing with terrestrial measurement and communication equipments, shipborne measurement and communication equipments work in more abominable environment and need more fence measures, such as "Three Fence". So the shipborne equipments are more complex and their costs are higher, especially need more reliable on their performance. For ensuring well-balanced functions of space measurement ships, we should compensate for the abrasion of the equipment.

Technical and economical analysis of equipment renewal means research on maintenance and update of the equipments which are based on capital expedition and work efficiency ullage. When analyzing maintenance and update strategy of the equipments, we look from the aspect of technical and economic technology. Firstly, we will apprehend correlative conceptions of equipment attrition and technical and economic analysis of maintenance and update on the equipment. Secondly, we analyze maintenance and update renewal strategy from the fee aspect. Thirdly, we choose the best scheme with the satisfaction of technical and work efficiency requirements [1].

The renewals are motivated mostly by requirement of space missions at present. But for continuable development the ratio of efficient and cost is important. The paper proposes the problem of technical and economic analysis of the renewals. The maintenance and update with their analysis are introduced too. Finally schemes of the renewal and its decision-making method are presented. The example proves the method is feasible and effective.

\section{MaintenANCE AND Update With Their TeCHNICAL AND ECONOMIC ANALYSIS}

From the aspect of technical and economic analysis, technical status of measurement and communication equipments turn gradually worse, and their value and usage decrease from time to time. The phenomenon is entitled “equipment abrasion". Abrasions are divided into material and immaterial ones. Entity abrasion of measurement and communication equipments which comes into being in use phase is called material abrasion. Immaterial abrasion is not influenced by usage and isn't exhibited in changes of entity but depreciation of original value [2].

To keep well-balanced status of measurement and communication function of the ships, abrasion of equipments should be compensated. The compensation of equipment abrasion has some different forms, including part compensation and entire compensation. The part compensation measure of the equipments' material abrasion is repair and the one of immaterial abrasion is technique update. The entire compensation measure of material and immaterial abrasion is to renew all, which means whole equipment will be eliminated and replaced by new one. If equipment's abrasion is eliminated by routine maintenance, it is needless to renew equipment.

\section{A. Maintenance with Analysis of Technical and Economic}

Equipment maintenance means renewing functions of parts or whole machine to reach original technique performance by adjusting or repairing original parts that have been abrased. Equipment's usage time may be prolonged by maintenance. But it's not limitless in technique and economy. That means equipment performance turn worse along with maintenance, as described in Figure 1. The equipment 
performance decreases from point $A_{0}$ to point $B$ in usage time. After repairing the equipment performance steps up from $B$ to $B_{1}$, but $B_{1}<A_{0}$, which can be observed in the figure. It indicates that the original status of equipment's performance can resume through maintenance but can't come back entirely.

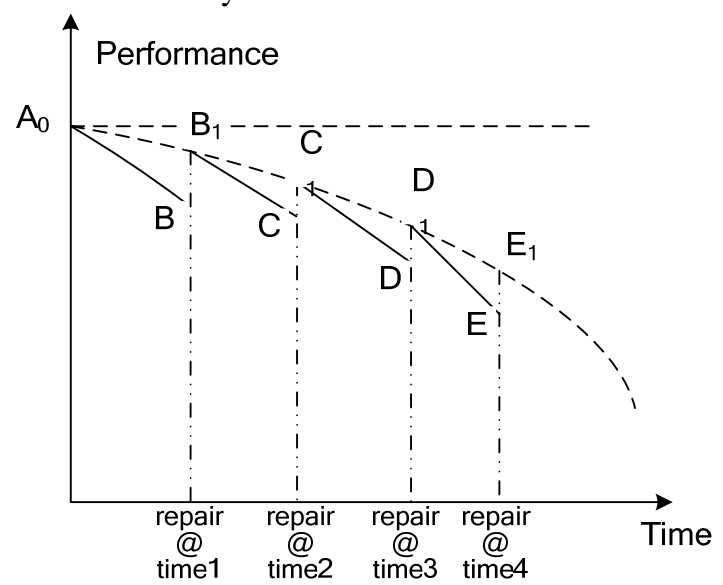

Figure 1. Equipment's performance degrades gradually along with time.

\section{B. Update with Analysis of Technical and Economic}

Modernization update means to change equipment's structure and boost technique performance to reach new equipment's work level by applying modern technology and advanced experience in order to fulfill requirement of equipment's function [3]. Modernization update is superior in economy and has crucial realistic meaning especially when renewal outlay is finite.

On one hand, it will generate purchase cost before using equipments which should be recouped in term of year in usage phase. The recouped cost is called yearly capital comeback cost. On the other hand, it will generate maintenance and management costs in equipment's usage phase which ensure equipment running in normal status. The costs are called yearly running cost. From the angle of technical economy, yearly capital comeback cost and yearly running cost make up of yearly total cost. And the mutative rule of the costs may be shown as Figure 2 .

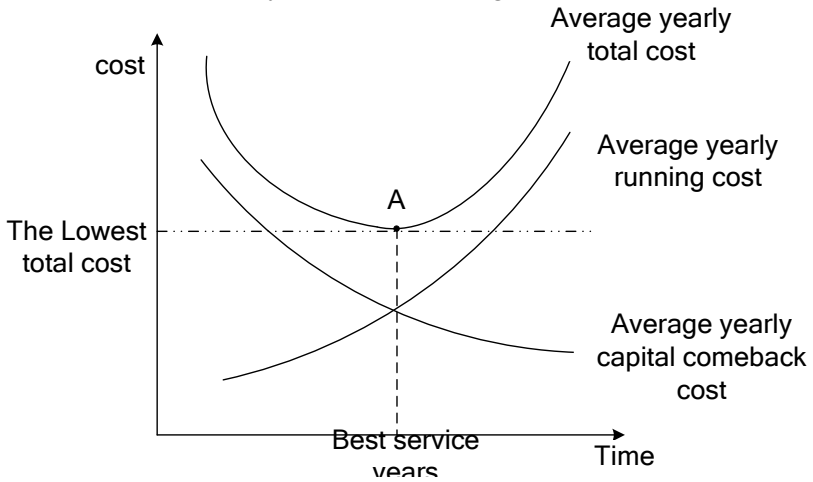

Figure 2. Equipment's cost changes along with its usage time.

\section{Renewal Schemes with Analysis of Technical and Economic}

Equipment renewal is a general compensation measure for its abrasion, which can promote technique, save outlays and enhance guarantee ability [4]. There may be some schemes for maintenance and update of measurement and communication equipments. The basic criterion of comparing these schemes is that the scheme must satisfy space mission requirement. Then renewal schemes can compare usage cost in the same scratch line. The best renewal scheme should have smallest yearly use cost comparing with others that satisfy technique and efficiency requirements.

Average yearly total cost of the equipment decreases firstly and then ascends in the running years as shown in Figure 2. When average yearly total cost of the equipment decreases to the lowest point, we get the equipment's best service years, which is named economy life-span. Economy life-span means the time we should renew the equipment. When we get use life-span, original value, residual value and yearly running cost of old and new equipment, we may propose some renewal schemes and select the best scheme.

\section{DECISION-MAKING OF RENEWAL SCHEMES}

\section{A. Cost Model of Renewal Schemes}

When estimating the cost of shipborne measurement and communication equipments in use stage, we should consider inflation rate, interest rate, exchange rate and tax. These factors will come into one factor namely capital's time value. Considering the flowage of capital in equipment's usage time, actual value of capital is relating with temporal time tightly, which means capital has time value attribute [5].

It should be studied further whether or not to renew it when the equipment exceeds the best service years. There are five schemes to be selected as follows: 1) Continue to use present equipment; 2) Big repair of the equipment; 3) Original type renewal of the equipment; 4) New type with higher efficiency renewal of the equipment; 5) Modern reconstruction of the equipment, namely equipments' technique renewal.

Equipment's manager should make proper decision on selecting a renewal scheme. The scheme delays the time with the lowest total cost and should consider capital's time value. It means that Technical \& Economical analysis based on present value of total cost is reasonable [6].

The formulas of calculating total cost of the schemes are shown in Table I. 
TABLE I. THE FORMULAS OF CALCULATING TOTAL COST OF THE SCHEMES

\begin{tabular}{|c|l|l|}
\hline Number & Renewal scheme & Formula \\
\hline 1 & Continue to use present equipment & $T C_{o}=\frac{1}{\beta_{o}}\left[\sum C_{o j} r_{j}-V_{o L} r_{n}\right]$ \\
\hline 2 & Big repair of the equipment & $T C_{r}=\frac{1}{\beta_{r}}\left[\left(K_{r}+\sum_{j=1}^{n} C_{r j} r_{j}\right)-V_{r L} \times r_{n}\right]$ \\
\hline 3 & Original type renewal of the equipment & $T C_{n}=\frac{1}{\beta_{n}}\left[\left(K_{n}+\sum_{j=1}^{n} C_{n j} r_{j}\right)-V_{n L} \times r_{n}\right]$ \\
\hline 4 & $\begin{array}{l}\text { New type with higher efficiency renewal of the } \\
\text { equipment }\end{array}$ & $T C_{h}=\frac{1}{\beta_{h}}\left[\left(K_{h}+\sum_{j=1}^{n} C_{h j} r_{j}\right)-V_{h L} \times r_{n}\right]$ \\
\hline 5 & \begin{tabular}{l} 
Modern reconstruction of the equipment \\
\hline
\end{tabular} & $T C_{m}=\frac{1}{\beta_{m}}\left[\left(K_{m}+\sum_{j=1}^{n} C_{m j} r_{j}\right)-V_{m L} \times r_{n}\right]$ \\
\hline
\end{tabular}

In Table I, $K_{r}, K_{n}, K_{h}, K_{m}$ are investments of the schemes; $C_{o j}, C_{r j}, C_{n j}, C_{h j}, C_{m j}$ are $j^{\text {th }}$ year's running costs of the schemes; $V_{o L}, V_{r L}, V_{n L}, V_{h L}, V_{m L}$ are $n^{\text {th }}$ year's residual value of equipment of the schemes; $\beta_{r}, \beta_{n}$, $\beta_{h}, \beta_{m}$ are work efficiency coefficients of the schemes; $r_{j}, r_{n}$ are $j^{\text {th }}$ and $n^{\text {th }}$ year's present value coefficients, as $r_{j}=1 /\left(1+i_{0}\right)^{j}$ and $r_{n}=1 /\left(1+i_{0}\right)^{n} ; i_{0}$ is a discounted rate of present value, which always named normal yield and is a converting parameter considering capital's time value.

The principle of selecting scheme is "Lowest Present Value of Total Cost”, which is simple and reasonable.

\section{B. Example with Its Analysis}

For all kinds of schemes of renewing a radar in space measurement ship, its cost and other parameters' original data are set in Table II.

TABLE II. ORIGINAL DATA OF FIVE RENEWAL SCHEMES

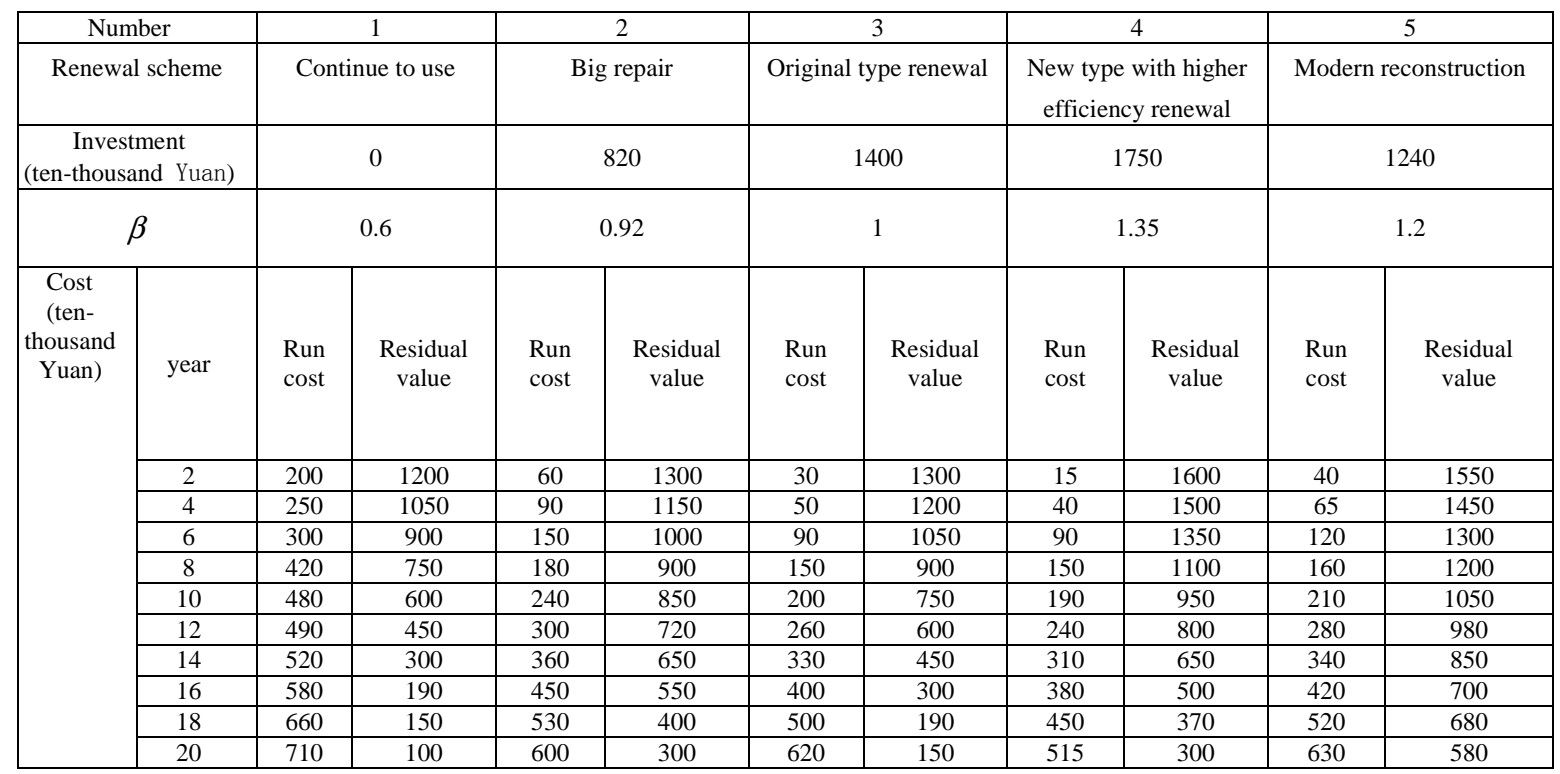

Referring to cost analysis model in section III.A, the costs are analyzed and calculated. The schemes are studied. In the model discounted present rate $i_{0}$ is set as $12 \%$. Calculation and the results of the model parameters in detailed are passed over. Final results of every scheme are gathered and shown in Table III.

Some results can be acquired through analyzing the data in Table III. Suppose that the radar use only 6 years as proposed (the equipment will be replaced by new one after 6 
years), scheme 1 (continue to use present one) is the best scheme. It is needless to make big repair or update. And the equipment could be discarded as useless after 6 years. But usage life-span of shipborne measurement and communication equipment is always more than 6 years. So the cost data of 20 years are calculated for reference here. The data in Table 3 shows that if the service years are from 8 to 16 years, big repair of the equipment is the best scheme. When service time is over 20 years, for example 30 years around, the best scheme may change. Whether it's original type renewal or new type with higher efficiency renewal, the entire compensation for the equipment's abrasion is out of commission.

TABLE III. PRESENT VALUE OF EACH SCHEME’S COST ALONG WITH TIME (UNIT: TEN-THOUSAND YUAN)

\begin{tabular}{|c|c|c|c|c|c|c|c|}
\hline \multicolumn{2}{|c|}{ Number } & 1 & 2 & 3 & 4 & 5 & \\
\hline \multicolumn{2}{|c|}{ Renewal scheme } & Continue to & Big repair & Original type & New type with & Modern & Least PV \\
\hline \multirow{10}{*}{$\begin{array}{c}\text { service } \\
\text { years }\end{array}$} & 2 & -1488.1 & -312.112 & 266.0714 & 248.0159 & -90.1786 & 1 \\
\hline & 4 & -765.306 & 31.02817 & 510.0128 & 444.0665 & 143.0006 & 1 \\
\hline & 6 & -81.9971 & 311.6677 & 756.5507 & 655.5886 & 376.5974 & 1 \\
\hline & 8 & 636.1383 & 509.9935 & 987.4217 & 896.5319 & 553.729 & 2 \\
\hline & 10 & 1317.051 & 639.4162 & 1183.243 & 1047.469 & 720.8703 & 2 \\
\hline & 12 & 1918.253 & 808.0406 & 1341.231 & 1165.998 & 837.0982 & 2 \\
\hline & 14 & 2464.088 & 913.9218 & 1477.442 & 1272.439 & 959.2988 & 2 \\
\hline & 16 & 2952.786 & 1024.41 & 1589.664 & 1364.268 & 1067.26 & 2 \\
\hline & 18 & 3387.201 & 1139.812 & 1673.342 & 1431.351 & 1126.611 & 5 \\
\hline & 20 & 3804.693 & 1204.038 & 1731.632 & 1467.777 & 1203.013 & 5 \\
\hline
\end{tabular}

\section{CONCLUSION}

Technical and economic analysis for renewal schemes of measurement and communication equipments in space measurement ship can ensure the best maintenance management pattern of the equipment in service years. It is helpful and meaningful for cost management task.

It is against continuable development considering more in technique and less in economic for the problem of the equipment renewal. When the maintenance and update scheme of the equipment is selected, we should not only consider original investment, use and maintenance costs, but also consider work efficiency, time value of capital, planning service life-span, etc. Present value of total cost of every scheme is analyzed in detailed and the management strategy of equipment maintenance is made based on technical and economic analysis theory in the paper. The decision-maker may refer the paper and select scientific scheme to renew shipborne measurement and communication equipment.

\section{REFERENCES}

[1] Maosheng $\mathrm{Hu}$, Yanping Feng, Yingliang Xie, et al. Theory and method of technical and economic. Peking: Metallurgical Industry Press, 2009.

[2] Tianzu Wu, Qin Feng and Zongjian Ouyang. Technical and economic analysis theory. Peking: Tsinghua University Press, 2005.

[3] Lihua Liu, Li Yan and Xianwei Yang. Economy life-span analysis of weapon equipments life circle management. Journal of the Academy of Equipment Command \& Technology, 2005, 16(1), pp 29-31.

[4] Maozhi Gan. Army equipment maintenance engineer. Peking: National Defense Industry Press, 1999.

[5] Li Xu. Technical and economic theory. Wuhan: Wuhan University Press, 2006.

[6] Zhonghai Sui and Zhenpo Wagng. Technical and economic analysis of pure-electric vehicles based on the life-cycle cost theory. Proceedings 2011 International Conference on Business Management and Electronic Information, p 125-129, 2011. 